23

\title{
Создание и определение чувствительности волоконно-оптического рефрактометра на основе поверхностного плазмонного резонанса
}

\author{
() М.Г. Гущин, Д.О. Гагаринова, С.А. Плясцов, Т.А. Вартанян \\ Университет ИТМО, \\ 197101 Санкт-Петербург, Россия \\ e-mail: magusch@gmail.com
}

Поступила в редакцию 07.05.2021 г.

В окончательной редакции 07.05.2021 г.

Принята к публикации 22.05.2021 г.

Создан волоконно-оптический датчик показателя преломления, использующий явление поверхностного плазмонного резонанса. На участок стандартного многомодового оптического волокна с частично зачищенной оболочкой был нанесены слой хрома толщиной $1 \mathrm{~nm}$ и золотая пленка толщиной $50 \mathrm{~nm}$. Измерены спектры пропускания в зависимости от показателя преломления внешней среды, в которую погружался датчик. При изменении показателя преломления внешней среды минимум в спектре пропускания, обусловленный возбуждением поверхностного плазмон-поляритона на границе между золотой пленкой и аналитом, смещался. Чувствительность сенсора составила $1400 \mathrm{~nm} / \mathrm{RIU}$.

Ключевые слова: плазмоника, оптическое волокно, сенсорика, поверхностный плазмонный резонанс, показатель преломления, золото.

DOI: $10.21883 /$ OS.2021.09.51353.2264-21

\section{Введение}

Определение показателей преломления относится к важнейшим оптическим методам характеризации вещества. Первый прибор, специально предназначенный для измерения показателя преломления - рефрактометр Аббе (Abbe) - был основан на явлении полного внутреннего отражения на границе между прозрачной средой, как правило, стеклом с известным показателем преломления $n_{g}$, и исследуемым веществом, которое приводится в непосредственный контакт с плоской стеклянной поверхностью. В зависимости от показателя преломления исследуемого вещества (аналита) $n_{a}$ изменяется критический угол полного внутреннего отражения $\theta_{c}$, который измеряется с необходимой точностью. Разумеется, с помощью рефрактометра Аббе можно измерять показатели преломления, меньшие, чем показатель преломления стекла, использованного в приборе. Чувствительность таких измерений, т. е. отношение приращения угла полного внутреннего отражения к приращению показателя преломления аналита, полностью определяется единственным параметром - показателем преломления стекла и близостью к нему показателя преломления аналита. Это легко видеть из формулы для критического угла полного внутреннего отражения $n_{g} \sin \left(\theta_{c}\right)=n_{a}$. Дифференцирование приведенной выше формулы дает чувствительность $d \theta_{c} / d n_{a}=1 / n_{g} \cos \left(\theta_{c}\right)=1 / \sqrt{n_{g}^{2}-n_{a}^{2}}$, которая формально неограниченно растет, когда угол полного внутреннего отражения приближается к $90^{\circ}$. Практически же чувствительность ограничена из-за угловой расходимости используемого излучения. Рефрактометры, действие которых основано на описанном выше принципе, стали коммерчески доступными в конце 19-го века.

В 1959 г. было впервые обращено внимание на то, что при нанесении на поверхность стекла тонкой металлической пленки полное внутреннее отражение не просто нарушается, а может быть сведено к нулю при определенном угле, превышающем, угол полного внутреннего отражения, и определенной толщине слоя металла [1]. Впоследствии это явление было связано c возбуждением поверхностного плазмон-поляритона (SPP) на свободной границе металлической пленки [2]. Поскольку угол, при котором наиболее эффективно возбуждается поверхностный плазмон-поляритон, зависит от показателя преломления среды, примыкающей к металлической пленке, на основе этого явления были разработаны рефрактометры [3], которые стали коммерчески доступными (Biacore) в 1990 г.

Угол падения света на границу стекло-металл, при котором на границе металл-аналит возбуждается поверхностный плазмон-поляритон, может быть рассчитан [2] по формуле

$$
n_{g} \sin \left(\theta_{\mathrm{SPR}}\right)=\frac{1}{\sqrt{\frac{1}{n_{a}^{2}}+\frac{1}{\operatorname{Re}(\varepsilon)}}},
$$

где $\varepsilon$ - диэлектрическая проницаемость металла, вещественная часть которой должна быть отрицательной и по модулю превосходить диэлектрическую проницаемость аналита $n_{a}^{2}$. Подкоренное выражение в указанных условиях положительно и больше $n_{a}$, так что $\theta_{\mathrm{SPR}}>\theta_{c}$. Появление в формуле (1) диэлектрической проницаемости металла, обладающего сильной дисперсией, открыло 
возможность измерения показателя преломления аналита не только по изменению угла $\theta_{\mathrm{SPR}}$, но и по изменению длины волны излучения $\lambda_{\mathrm{SPR}}$, на которой возникает наибольшее нарушение полного внутреннего отражения при неизменном угле падения света. Дифференцируя формулу (1), получим

$$
\frac{d \lambda_{\mathrm{SPR}}}{d n_{a}}=-\frac{2 \varepsilon^{2}}{n_{a}^{2}\left(\frac{d \varepsilon}{d \lambda}\right)} .
$$

Если дисперсия диэлектрической проницаемости металла хорошо описывается моделью Друде [2] с плазменной длиной волны $\lambda_{p}$, то на длинах волн, существенно больших $\lambda_{p},(2)$ сводится к [4]

$$
\frac{d \lambda_{\mathrm{SPR}}}{d n_{a}}=\frac{\lambda_{\mathrm{SPR}}^{2}}{n_{a}^{3} \lambda_{p}^{2}} .
$$

Оценки, выполненные на основе (3) для золота в видимой области спектра, дают значения спектральной чувствительности в тысячи нанометров на единицу показателя преломления, что достаточно для многих применений.

Зависимость спектрального положения плазмонного резонанса от показателя преломления окружающей среды позволила предложить волоконно-оптические сенсоры показателя преломления на основе поверхностного плазмонного резонанса [5]. Для того чтобы нанести металлическую пленку на сердцевину оптического волокна, с небольшого участка волокна удаляют оболочку. Особенностью волоконно-оптического датчика является то, что углы падения лучей на металлическую поверхность нельзя зафиксировать. В многомодовом волокне многообразие направляемых мод приводит к тому, что углы падения излучения на металлическую поверхность оказываются в диапазоне от скользящих до критического угла полного внутреннего отражения на границе сердцевина-оболочка. Согласно (1), при изменении угла падения изменяется и длина волны излучения, на которой резонансно возбуждается поверхностный плазмон-поляритон. Поэтому разброс углов падения излучения приводит соответствующему уширению плазмонного резонанса. Несмотря на это, уменьшение пропускания волокна в диапазоне длин волн, отвечающих резонансному возбуждению плазмон-поляритона, может быть зафиксировано экспериментально. Соответствующие расчеты и демонстрации неоднократно приводились в литературе [5-9], но коммерчески доступных рефрактометров на основе описанных эффектов до сих пор не существует.

В настоящей работе описано создание волоконнооптического сенсора показателя преломления на основе поверхностного плазмонного резонанса и приведены результаты исследования его чувствительности. Использовано стандартное многомодовое оптоволокно и простые операции по подготовки волокна и нанесению металлической пленки. Полученный сенсор обладает чувствительностью, достаточно высокой для разнообразных применений.

\section{Подготовка оптического волокна}

Для проведения экспериментальных исследований по измерению показателя преломления внешней среды при помощи поверхностного плазмонного резонанса было взято стандартное многомодовое оптическое волокно MMF 62,5/125. Был выбран метод механического снятия (полировки) части оболочки оптического волокна для обеспечения взаимодействия эванесцентного электромагнитного поля с аналитом. Участок оптического волокна крепился эпоксидной смолой в V-образную канавку подложки, изготовленной из фотополимера ANYCUBIC 3D Printer Resin, Basic на фотополимерном принтере. Полученную конструкцию - подложку с многомодовым оптическим волокном - полировали вручную при помощи девяти различных полировальных пленок (KWH MIRKA LTD, KLINGSPOR, AngstromLap), последовательно переходя от большей зернистости к меньшей, чтобы исключить образование царапин и трещин. Для мониторинга процесса полировки до его начала всю конструкцию при помощи оптических пигтейлов подключали к широкополосному источнику излучения QTh13MA1011 (AlphaBright, Великобритания) и измерителю мощности FOD-1204H (FOD, Литва). Процесс полировки продолжался до момента резкого спада пропускаемой мощности, что свидетельствовало об удалении оболочки. Длина сенсорного участка, на котором волокно приобрело форму латинской буквы D (D-shaped), составила $5 \mathrm{~mm}$. Образец сполированного сверху многомодового оптического волокна изображен на рис. 1.

\section{Напыление металлической пленки}

Подготовленное оптическое волокно вместе с подложкой помещалось в вакуумную камеру PVD-75 (Kurt J. Lesker, США), обеспечивавшую безмасляный вакуум на уровне $10^{-7}$ Torr. Известно, что тонкие золотые

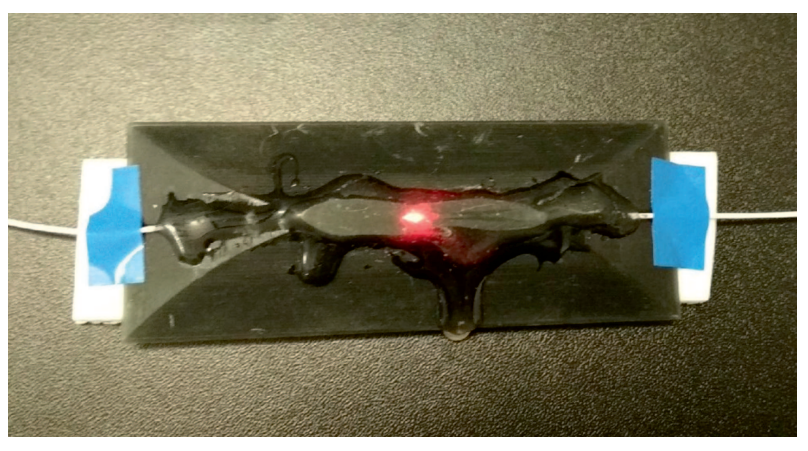

Рис. 1. Образец многомодового оптического волокна со снятой сверху оболочкой. Красное пятно в центре - это рассеянное на поверхностных неоднородностях поле распространяющихся по волокну мод. 
пленки при осаждении непосредственно на диэлектрические подложки растут по механизму Вольмера-Вебера с образованием большого количества наноразмерных гранул [10], что в данном случае неприемлемо. С тем чтобы получить сплошную золотую пленку и улучшить ее адгезию к волокну, на волокно предварительно был осаждён тонкий слой хрома. Хром осаждался при помощи электронно-лучевого испарителя до достижения толщины $1 \mathrm{~nm}$ по показаниям кварцевых микровесов. Затем в этой же установке методом термического напыления наносилось золото. Оптимальная скорость напыления $0.05 \mathrm{~nm} / \mathrm{s}$ была определена в предыдущих экспериментах [11]. Эквивалентная толщина осаждённого золота соответствовала $50 \mathrm{~nm}$, что позволяло достичь максимального контраста при возбуждении поверхностного плазмон-поляритона. Схематическая модель полученного образца изображена на рис. 2.

\section{Моделирование пропускания волоконно-оптического сенсора}

Детальный расчет пропускания оптического волокна с изготовленным сенсорным участком представляется достаточно трудной задачей, так как необходимо учитывать распространение множества лучей под разными углами и их многократные отражения от металлизированного и неметаллизированных участков волокна. Несмотря на это, качественное описание чувствительности изготовленного сенсора может быть получено, если учесть только однократное отражение света на том участке, где удалена оболочка и нанесена золотая пленка.

Расчетная модель изображена на рис. 3, на котором сердцевина волокна представлена полубесконечной средой с показателем преломления 1.5. Излучение,

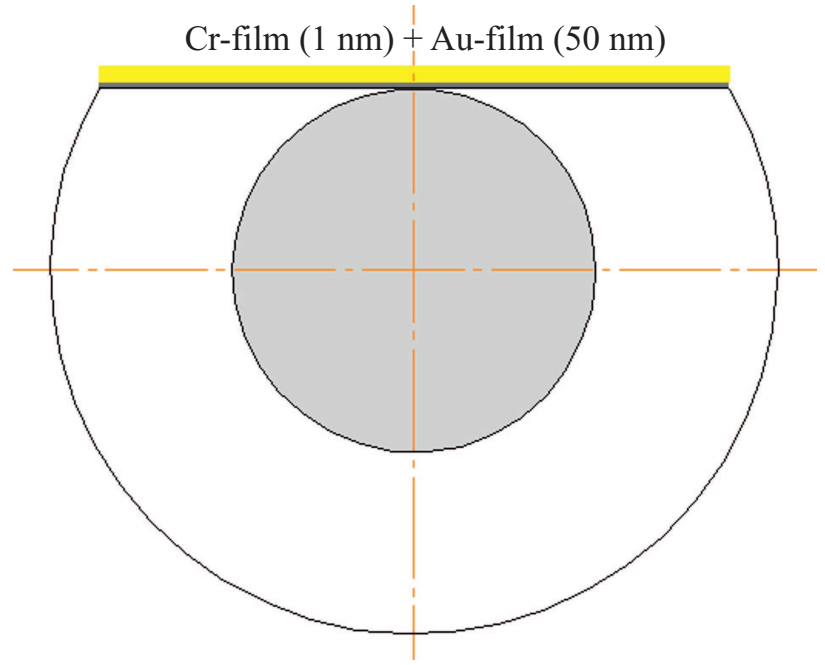

Pис. 2. Поперечное сечение многомодового оптического волокна с нанесенными слоями хрома $(1 \mathrm{~nm})$ и серебра $(50 \mathrm{~nm})$.

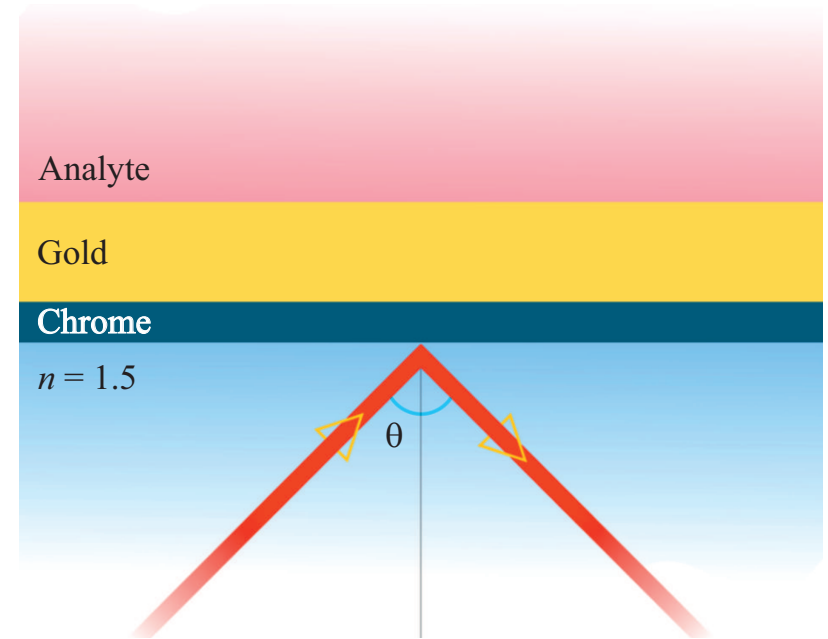

Рис. 3. Модель для расчета коэффициента отражения света от многослойной сенсорной структуры. Луч света падает из полубесконечной среды с показателем преломления 1.5, представляющей сердцевину оптического волокна. Слой хрома толщиной $1 \mathrm{~nm}$ обеспечивает адгезию золотой пленки и ее однородность. Оптимальная толщина золотой пленки $-50 \mathrm{~nm}$. Аналит в расчете был представлен как полубесконечная среда с определенным показателем преломления, меньшим показателя преломления сердцевины оптоволокна.

распространяющееся в сердцевине многомодового волокна, падает на его границы под различными углами, большими критического угла полного внутреннего отражения на границе сердцевина-оболочка. Поскольку числовая апертура использованного нами волокна MMF 62,5/125 составляет $\mathrm{NA}=0.276$, минимальный угол падения луча на металлическую пленку составляет $90-\sin ^{-1}(0.276)=74^{\circ}$.

Для расчета отражения света от многослойной структуры использовался матричный метод [12-14]. Оптические постоянные золота были взяты из [15], поскольку они были получены для золотой пленки близкой толщины, а хрома из [16]. На рис. 4 приведены спектры отражения сенсорного участка при контакте с аналитом с показателем преломления 1.37 и толщине золотой пленки $50 \mathrm{~nm}$ для нескольких углов падения излучения. Глубокий минимум коэффициента отражения обусловлен резонансным возбуждением поверхностного плазмон-поляритона на границе между золотой пленкой и аналитом. При толщинах золотой пленки, отличных от $50 \mathrm{~nm}$, провал в спектре коэффициента отражения оказывается не таким глубоким, поэтому указанная толщина оптимальна. Положение минимума отражения зависит от угла падения света, поэтому провал в спектре пропускания оптоволоконного сенсора, в котором распространяются лучи во всем указанном выше диапазоне углов, будет значительно шире, чем каждый из спектров, представленных на рис. 4, в отдельности. 
Для оценки чувствительности спектрального положения минимума коэффициента отражения к изменению показателя преломления аналита был выбран угол падения, равный $76^{\circ}$.

Результаты расчета спектров отражения для угла падения света $76^{\circ}$ при различных показателях преломления аналита в диапазоне 1.33-1.39 представлены на рис. 5, а на рис. 6 по этим данным построена зависимость спектрального положения минимума коэффициента отражения сенсорной структуры от показателя преломления аналита. В соответствии с (3) чувствительность спектрального положения плазмонного резонанса к изменению показателя преломления растет с увеличением длины волны. Диапазон чувствительности $1700-4000 \mathrm{~nm} / \mathrm{RIU}$ в зависимости от показателя преломления среды.

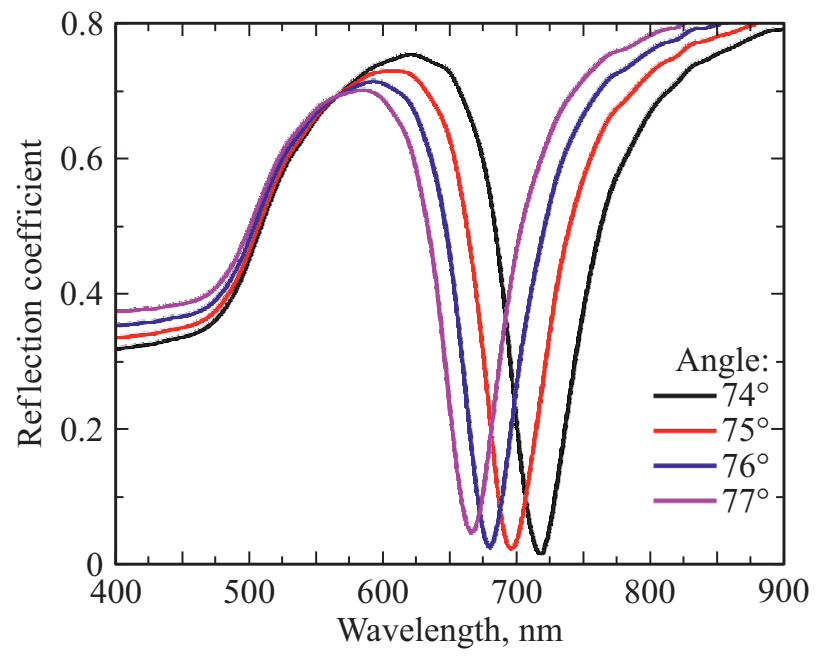

Pис. 4. Рассчитанные спектры отражения сенсорного участка волокна при различных углах падения излучения. Показатель преломления аналита 1.37. Углы падения излучения 74-76².

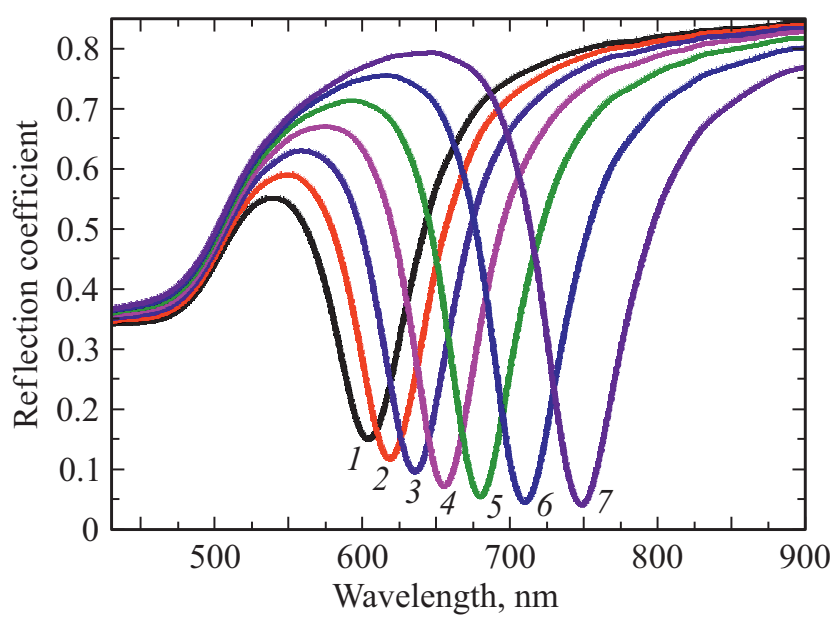

Pис. 5. Рассчитанные спектры отражения сенсорного участка волокна при изменении показателя преломления аналита. Угол падения света $76^{\circ}$. Показатель преломления среды: 1.33 (1), 1.34 (2), 1.35 (3), 1.36 (4), 1.37 (5), 1.38 (6), 1.39 (7).

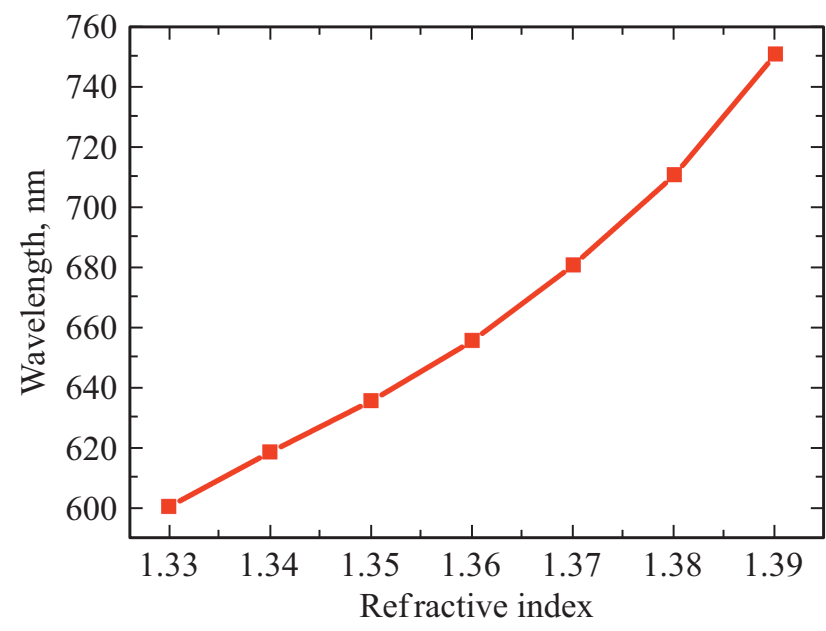

Рис. 6. Рассчитанная зависимость спектрального положения минимума коэффициента отражения сенсорной структуры от показателя преломления аналита. Угол падения света $76^{\circ}$.

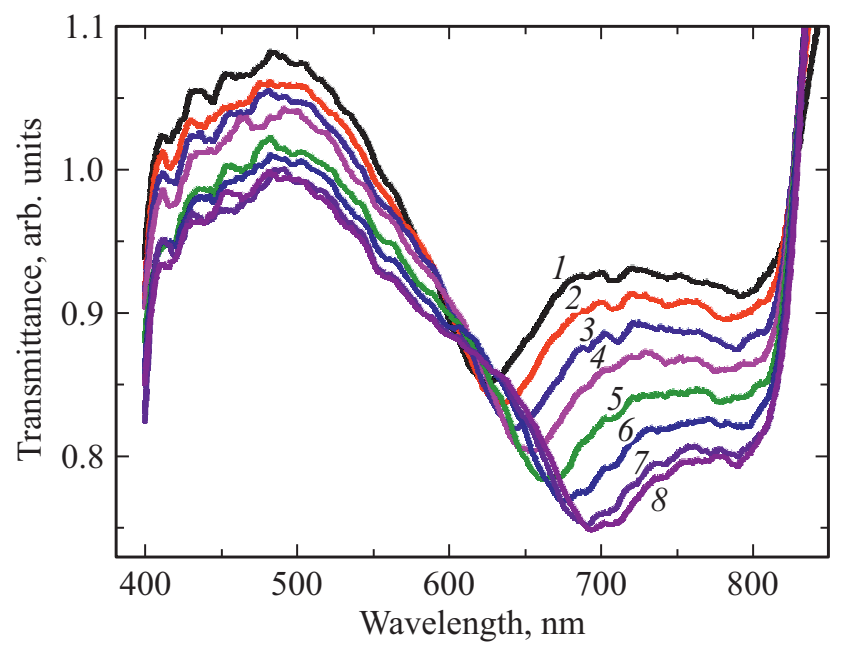

Рис. 7. Измеренные спектры пропускания волоконно-оптического сенсора в зависимости от показателя преломления раствора глюкозы. Показатель преломления раствора: 1.334 (1), 1.341 (2), 1.348 (3), 1.355 (4), 1.362 (5), 1.37 (6), 1.376 (7), $1.382(8)$.

\section{Испытание волоконно-оптического сенсора}

Действие созданного волоконно-оптического сенсора было проверено на растворах глюкозы, показатель преломления которых изменялся в зависимости от концентрации от 1.334 до 1.382 [17,18].

Свет в оптоволокно подавался широкополосным источником излучения QTh13MA1011 (AlphaBright, Beликобритания) под углом от $74^{\circ}$, спектр излучения, прошедшего через сенсор, регистрировался спектрофлуориметром Флюорат-02-Панорама (Люмэкс, Россия) в диапазоне от 360 до $850 \mathrm{~nm}$. Результаты измерений представлены на рис. 7 , а на рис. 8 построена зависимость 


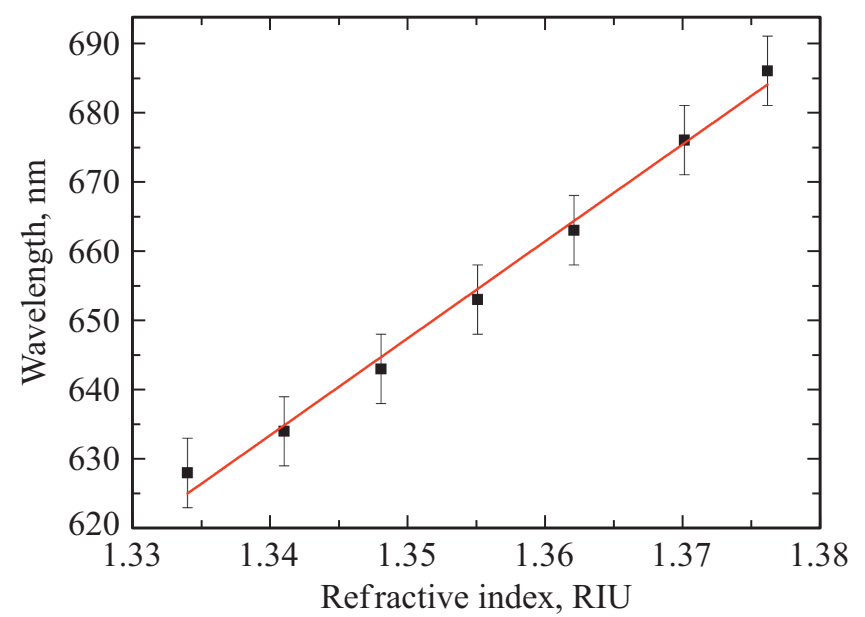

Рис. 8. Экспериментально полученная зависимость спектрального положения минимума пропускания волоконно-оптического сенсора от показателя преломления раствора глюкозы.

спектрального положения минимума пропускания сенсора от показателя преломления аналита. Линейная зависимость, отвечающая чувствительности $1400 \mathrm{~nm} / \mathrm{RIU}$, наблюдается во всем исследованном диапазоне показателей преломления аналита.

\section{Заключение}

В результате простых манипуляций стандартное многомодовое волокно превращено в датчик показателя преломления, который может стать основой для построения волоконно-оптического рефрактометра. Сдвиг минимума пропускания, обусловленный зависимостью условий возбуждения поверхностно плазмон-поляритона от показателя преломления аналита, сопровождается значительным изменением пропускания в широкой спектральной области, что может быть использовано для упрощения схемы регистрации. Низкие потери в оптическом волокне позволяют использовать такой датчик дистанционно, в том числе, в труднодоступных местах. Измерения могут производиться с высокой частотой повторения и пренебрежимо малой задержкой передачи данных. Небольшая глубина проникновения эванесцентного поля в аналит обеспечивает чувствительность волоконно-оптического сенсора к изменению показателя преломления в тонких слоях, непосредственно прилегающих к его поверхности. Последнее обстоятельство открывает возможности для биомедицинских применений при условии функционализации поверхности золотой пленки.

\section{Конфликт интересов}

Авторы заявляют, что у них нет конфликта интересов.

\section{Список литературы}

[1] Turbadar T. // Proc. Phys. Soc. 1959. V. 73. P. 40-44.

[2] Raether H. Surface Plasmons on Smooth and Rough Surfaces and on Gratings, Berlin, Heidelberg: Springer, 1988.

[3] Liedberg B., Nylander C., Lundstrom I. // Sens. Actuators. 1983. V. 4. P. 299-304.

[4] Homola J. // Sens. Actuators. B. 1997. V. 41. P. 207-211.

[5] Iga M., Seki A., Watanabe K. // Sens. Actuators. B. 2005. V. 106. P. 363-368.

[6] Apriyanto H., Ravet G., Bernal O.D., Cattoen M., Seat H.C., Chavagnac V., Surre F., Sharp J.H. // Scientific Reports. 2018. V. 8. N 1. P. 1-3.

[7] Cennamo N., Varriale A., Pennacchio A., Staiano M., Massarotti D., Zeni L., D'Auria S. // Sens. Actuators. B: Chemical. 2013. V. 176. P. 1008-1014.

[8] Esteban O., Naranjo F.B., Díaz-Herrera N. // Sens. Actuators. B. 2011. V. 158. P. 372-376.

[9] Mitsuhiro I., Atsushi S., Kazuhiro W. // Sens. Actuators. B. 2005. V. 106. N 1. P. 363-368.

[10] Leonov N.B., Gladskikh I.A., Polishchuk V.A., Vartanyan T.A. // Opt. and Spectrosc. 2015. V. 119. N 3. P. $450-455$.

[11] Гладских И.А., Вартанян Т.А. // Опт. и спектр. 2016. T. 121. № 6. P. 916-921.

[12] Steed R.J. Transfer Matrix Theory for a Type of Uniaxial Layers: Starting from Basic Electromagnetism, 2013.

[13] Борн М., Вольф Э. Основы оптики. М.: Наука, 1973.

[14] Byrnes S.J. Multilayer optical calculations, 2016. https://arxiv.org/abs/1603.02720

[15] Yakubovsky D.I., Arsenin A.V., Stebunov Y.V., Fedyanin D.Y., Volkov V.S. // Opt. Express. 2017. V. 25. P. 25574-25587.

[16] Johnson P.B., Christy R.W. // Phys. Rev. B. 1974. V. 9. P. 5056-5070.

[17] Иофбе Б. Рефрактометрические методы химии. Л.: ГНТИ Химической литературы, 1960.

[18] Sucrose, Refractometry concentration table $\left(+20^{\circ} \mathrm{C}\right)$, METTLER TOLEDO, электронный ресурс: https:/www.mt.com/ru/ru/home/supportive_content/ concentration-tables-ana/Sucrose_re_e.html. [Дата обращения: 2021]. 